\title{
Diagnosis of Breast Micro calcifications with Contrast Enhanced Digital Mammography and Histopathological Correlation
}

\author{
HANA HAMDY NASSEF, M.D.; AMIR LOUIS LOUKA, M.D. and AMIRA LOTAIF ABDULLAH, M.Sc.
}

The Department of Radiodiagnosis, Faculty of Medicine, Ain Shams University

\begin{abstract}
Backgroud: Microcalcificaitons constitute up to $31 \%$ of lesions detected at screening mammography. Ductal carcinoma in situ (DCIS) often presents with microcalcificaitons on mammography. Of all mammographically detected DCIS lesions, up to $79 \%$ manifest with microcalcifications only. However, not all microcalficications are associated with in situ or malignant disease.
\end{abstract}

Aim of Study: To evaluate diagnostic value of contrast enhanced digital mammography in breast microcalcificaations.

Methods: A retrospective study of 30 patients having mammographic suspicious breast calcifications under BIRADS 4,5 and 6 categories. A high-energy and a low-energy digital mammograms were obtained and then images were subtracted, isolating the iodine signal in the region of angiogenesis. $1.5 \mathrm{mg} / \mathrm{kg}$ of the contrast agent was injected by hand over a period of 1 minute at a rate of $3 \mathrm{~mL}$ per second, followed by a saline solution flush. Breast compression was applied to reduce the thickness of the breast and images obtained exactly 2 min after contrast administration. Image acquisitions: Craniocaudal and the medio-lateral oblique projections for the abnormal breast were obtained exactly 2 minutes after contrast injection followed by cranio-caudal and medio-lateral oblique projections of the normal breast. The lesions were analyzed by specialized radiologist for the presence, morphology, and pattern of enhancement. Finally, Correlation with histopathological findings was done.

Results: The sensitivity of CEDM in detecting malignant pathology with contrast uptake was $96 \%$. Compared to sensitivity of $86.7 \%$ in FFDM. There were lesions of IDC in $(69.2 \%)$, lesion of DCIS in (11.5\%), lesion of IDCS \& IDC in $(11.5 \%)$ and lesions of ILC in $(3.8 \%)$. Enhancement was also observed in $3 / 4(75 \%)$ of the benign lesions.

Conclusion: Dual-energy contrast-enhanced digital mammography is a useful technique in the diagnosis of underlying disease in mammographically detected breast microcalcifications.

Key Words: Microcalcifications - Contrast enhanced digital mammography - Ductal carcinoma insitu.

Correspondence to: Dr. Amira Lotaif Abdullah E-Mail: amiralotaiff@gmail.com

\section{Introduction}

MICROCALCIFICAITONS are a common finding on mammography and constitute up to $31 \%$ of lesions detected at screening mammography [1]

Ductal carcinoma in situ (DCIS), a potential precursor lesion of invasive ductal carcinoma, often presents with microcalcificaitons on mammography. Of all mammographically detected DCIS lesions, up to $79 \%$ manifest with microcalcifications only [1]

Therefore, careful evaluation of mammogrpahically detected microcalcifications is essential. However, not all microcalficications are associated with in situ or malignant disease [2].

Contrast enhanced digital mammography (CEDM) is a relatively new contrast-enhanced technology for breast imaging and holds great promise for assessing clinical indications similar to those of breast MRI [3].

Contrast enhanced mammography generates a high-resolution, low-energy, full-filled digital mammography image [4]. Post iodinated contrast recombined image is used to assess tumor neovascualrity [5]

Aim of the work:

The purpose of this study is to evaluate diagnostic value of contrast enhanced digital mammography in breast microcalcificaations.

\section{Patients and Methods}

This study was retrospectively carried on 30 female patients during the time interval of January 2019 till June 2019 at radiology department, Ain Shams University Hospitals. The study population's age range was 34-67 years with a mean age of 
$51.27 \pm 9.24$ (mean \pm SD). The Patients who had CEDM examinations were those having mammographic suspicious breast calcifications under BIRADS 4, 5 and 6 categories.

The study was done according to the regulations of the ethical committee, patients were well informed in details about the examination concerning the procedure and the possible risks, urea and creatinine as renal function test was mandatory to be within normal values.

\section{Inclusion criteria:}

Women with suspicious microcalcifications detected at mammography or breast sonography.

\section{Exclusion criteria:}

- Pregnancy or possible pregnancy.

- History of allergy to an iodinated contrast agent.

- Patients with impaired renal function.

All patients were submitted to the following:

I- Data collection:

- Demographic data was collected (patient's name, age, marital status \& number of offspring, residence $\&$ phone number).

- Full clinical history taking regarding the clinical presentation, duration of complaint, age, family and past history, presence of other diseases or any taken medications.

\section{II- Clinical examination:}

Physical examination was done by a specialized breast surgeon.

\section{III- Pathologic diagnosis:}

Pathologic analysis of samples of breast lesions was performed in Ain Shams University Hospitals, Pathology Department by a group of expert pathologists. Samples were obtained with core biopsy, true cut biopsy and post-surgical pathology specimen.

\section{IV- Imaging procedures:}

All patients were assessed by mammography and complementary ultrasonography. Then CEDM was performed using dual energy technique.

\section{Contrast agent:}

The contrast agent used is the nonionic solution (Omnipaque 300; Nycomed, Roskilde, Denmark) a nonionic solution containing $300 \mathrm{mg}$ of iodine per milliliter, which is commonly used for CT. In our study, we injected $100 \mathrm{~mL}$ of the agent by hand over a period of approximately 1 minute.

\section{Equipments:}

The contrast enhanced mammography studies were performed with a device developed by GE Healthcare allowing dual-energy CEDM acquisitions (Senographe $2000 \mathrm{D}$ full field digital mammography Essential GE Healthcare).

With a current full-field digital mammography system using a flat panel detector with CsI absorber, field size 19x23, del pitch of $100 \mathrm{~mm}$, image matrix size 1,914x2,294 (Senographe DS), with some specific software adaptations for acquisition and image processing.

The digital mammography system was modified by adding a copper filter specifically used for CEDM, in addition to the usual molybdenum and rhodium filters used for standard mammography. Moreover, a high voltage range of $45-49 \mathrm{kVp}$ was used (instead of $26-32 \mathrm{kVp}$ for conventional digital mammography). For a $5 \mathrm{~cm}$-thick, $50 \%$ glandular breasts, exposure times were around 1 second and 3 seconds for the low and high energy images, respectively.

A catheter was inserted into the antecubital vein of the arm contra-lateral to the breast of concern. A one-shot intravenous injection of $1.5 \mathrm{ml} /$ body weighted of non-ionic contrast agent was then performed, manual injection injector applied. A pair of low- and high-energy exposures was performed up to 9 minutes for acquisition of post injection images, the breast was compressed in a $\mathrm{CC}$ position of breast of concern then another CC view of the other breast. Then view of breast of concern in MLO position and last view of other breast in MLO position. A combination of lowenergy and high-energy images through a specific image processing was performed in order to generate two subtracted images with contrast agent uptake information (one in the MLO and one in the $\mathrm{CC}$ view).

\section{Techniques:}

Typically, the contrast-enhanced digital mammographic procedure was performed in approximately 11-15 minutes.

This included 3 minutes for placement of the intravenous catheter, 1 minute for obtaining the mask image, 1 minute or more for completion of the injection, and up to 9 minutes for acquisition of post-injection images.

The breast was lightly compressed in the craniocaudal projection for the duration of the examination, with enough pressure to limit anatomic motion but not enough to significantly reduce blood flow. 
An initial reference or scout mammogram was obtained with normal mammographic parameters, typically $26-32 \mathrm{keV}$, and the appropriate target and filter. The purpose of obtaining this image was to provide information regarding the soft-tissue anatomy and to provide anatomic reference points for the subsequent images that were to be obtained with identical conditions of positioning and compression.

The exposure factors were adjusted to produce an $\mathrm{X}$-ray beam containing as high a fraction of $\mathrm{X}$ -rays above the $\mathrm{k}$ absorption edge of iodine $(33 \mathrm{keV})$ as possible. With the prototype system, exposures were obtained at $45 \mathrm{keV}$, with a tungsten target, filtered with $0.13 \mathrm{~mm}$ of holmium and $2 \mathrm{~mm}$ of aluminum, whereas with the production system, the molybdenum target was used with a varying kilo-voltage of $45-49 \mathrm{keV}$ and a molybdenum anode with added copper and aluminum filtration.

A single mask image was then produced. Immediately following this exposure, the patients received an injection of $100 \mathrm{~mL}$ of contrast that was administered in the antecubital vein of the arm contralateral to the breast of concern. Immediately after completion of the injection, the first postcontrast image was obtained.

A second postcontrast image was obtained 2 minutes later at 3 minutes, and then subsequent images were obtained at 5, 7, and 10 minutes; a total of six images for each patient in addition to the scout image were produced.

The milliampere-second setting for each patient was chosen according to the thickness and composition of the breast, but once selected, it was kept constant for the mask and postcontrast images. The total radiation dose for the six images was approximately equivalent to that from a single screen-film mammographic image.

\section{Image analysis:}

An expert radiologist gave an assessment using Image Diagnostic Workstation for the pre contrast images of the lesion as regards the presence of focal asymmetry, margins, density, architectural distortion, lesion extensions, microcalcifications (shape and distribution), number of lesions \& skin infiltration.

The subtracted CEDM images were reviewed using reading criteria based on pattern of enhancement (mass or non mass-enhancement), intensity of enhancement (faint, intermediate, intense) as well as morphology of microcalcifications (pleomorphic, fine linear, amorphous and coarse heterogeneous).

\section{Diagnostic criteria:}

The reference standard was the histopathological analysis of the biopsy sample results.

\section{Statistical analysis:}

Data were statistically described in terms of sensitivity.

Statistical analysis was done using IBM SPSS Statistics program" version 22".

Chi square $\left(\mathrm{X}^{2}\right)$ test was used to describe the impact of different morphological characters of the lesions on the diagnosis of them. All the statistical tests were done at .001 level of significance.

The primary unit of analysis was microcalcification, abnormality described in all cases as benign or malignant.

Lesions with a diagnosis of duct ectasia, inflammatory (granulomatous mastitis) and hyperplasia were classified as being benign for statistical analysis.

Lesions with a diagnosis of ductal carcinoma insitu, invasive ductal carcinoma, lobular carcinoma in situ and invasive lobuar carcinoma were classified as being malignant for statistical analysis.

Sensitivity was estimated taking the probability of BI-RADS 4 or higher as positive test results.

Comparisons of sensitivity between histopathology results and CEDM were made.

\section{Results}

The ACR breast density in the diagnostic mammographic examinations was classified as follows: ACR A entirely fatty breast in 1/30 (3.3\%), ACR B fibroglandular in 14/30 (46.7\%), ACR C scattered dense in 13/30 (43.3\%) and ACR D extremely dense in $2 / 30(6.7 \%)$ of patients. Fig. (1).

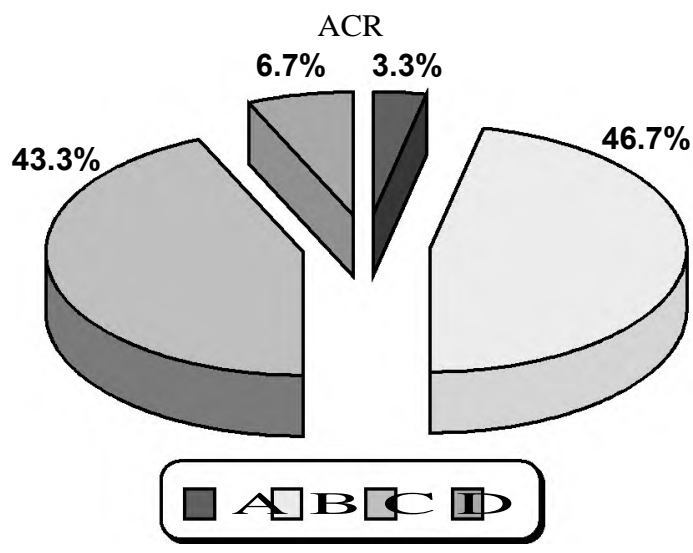

Fig. (1): ACR classification of breast density. 
The pathology results showed that $26 / 30$ $(86.7 \%)$ were malignant and $4 / 30(13.3 \%)$ were benign. Table (1), Fig. (2).

Table (1): Total number of benign and malignant lesions.

\begin{tabular}{ll}
\hline Malignancy & No.=30 \\
\hline Benign & $4(13.3 \%)$ \\
Malignant & $26(86.7 \%)$ \\
\hline Total & $30(100.0 \%)$ \\
\hline
\end{tabular}

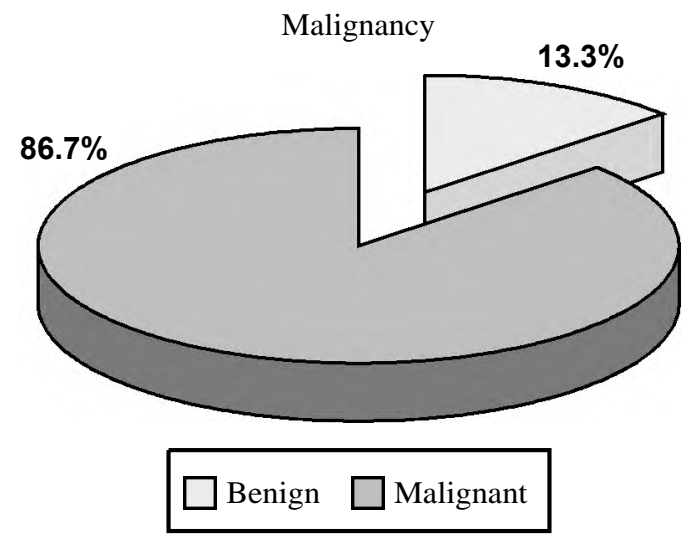

Fig. (2): Total number of benign and malignant lesions.

The pathology results revealed 18/30 (60\%) lesions of IDC, $3 / 30(10 \%)$ lesion were DCIS, $3 / 30$ $(10 \%)$ were DCIS + IDC, $1 / 30(3.3 \%)$ ILC, $1 / 30$ $(3.3 \%)$ lesion of undifferentiated carcinoma, $2 / 30$ $(6.7 \%)$ were diagnosed with duct ectasia, $1 / 30$ (3.3\%) atypical hyperplasia and $1 / 30(3.3 \%)$ case of periductal mastitis. Fig. (3).

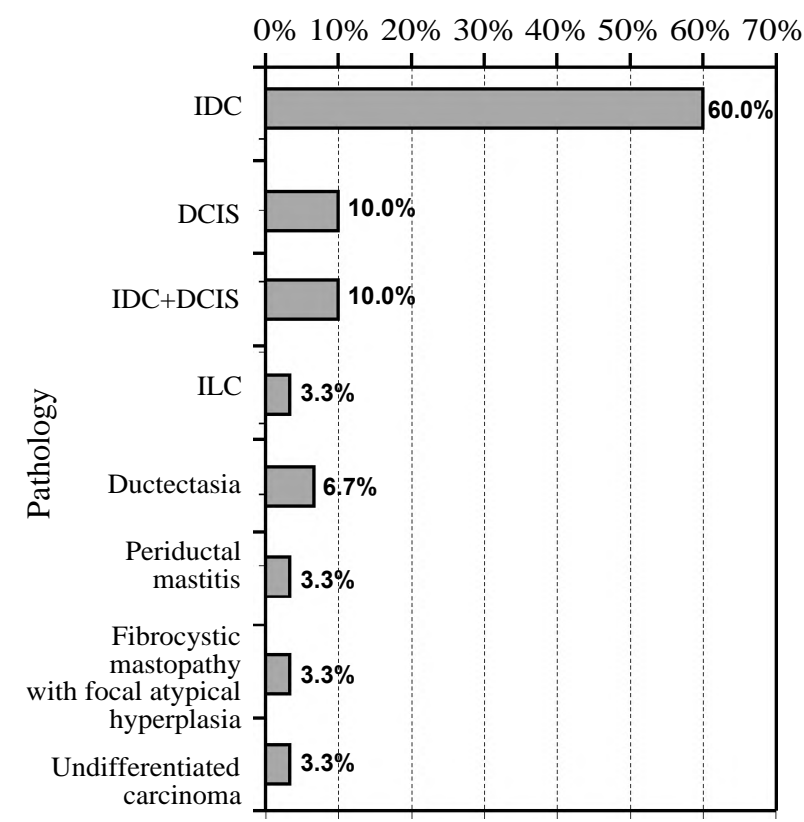

Fig. (3): Distribution of lesions according to pathology diagnosis.
CEDM showed no enhancement in 2/30 (6.7\%), mass enhancement in $26 / 30(86.75 \%)$ and non mass enhancement in 2 (6.7\%). Fig. (4).

Enhancement or not

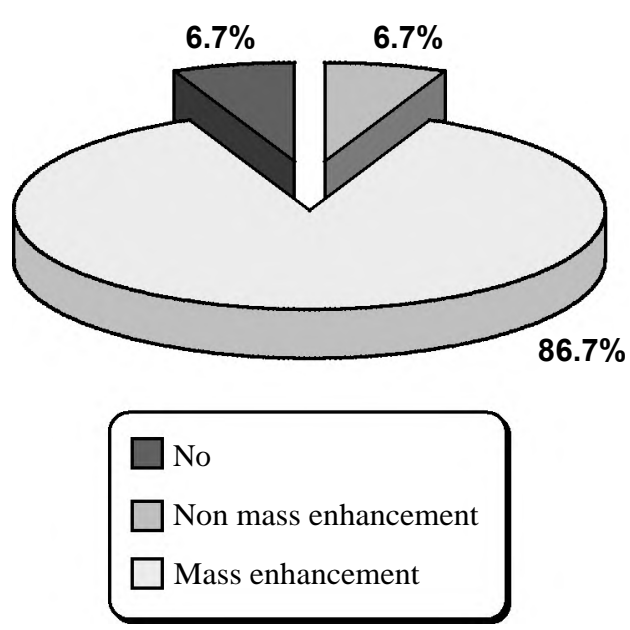

Fig. (4): CEDM enhancement of all cases.

CEDM Enhancement was 25/30 (96.2\%) malignant lesions. Corresponding to $18 / 30(69.2 \%)$ lesions of IDC, $3 / 30(11.5 \%)$ lesion of DCIS, $3 / 30$ $(11.5 \%)$ lesion of IDCS \& IDC, $1 / 30(3.8 \%)$ lesion of ILC.

Enhancement was also observed in 3/30 (9.9\%) benign lesions corresponding to $2 / 30$ $(6.6 \%)$ lesion of ductectasia, 1/30 (3.3\%) periductal mastitis.

Out of the two no enhancement lesions one was malignant case of undifferentiated carcinoma and the other one was a benign case of atypical hyperplasia.

The morphologic classification of lesions presented as follows: Fine linear/branching, 4 (13\%) of the 30 cases all of which are malignant; fine pleomorphic, $6(20 \%)$ all malignant, coarse heterogeneous, 1 (3\%) malignant case; amorphus 19 (63\%) which was $4 / 19(21 \%)$ benign cases and 15 (79\%) malignant cases; and typically benign, zero $(0 \%)$ of the 30 cases. Fig. (5).

Regarding the intensity of enhancement; $38.5 \%$ of the malignant lesions showed intense enhancement, $26.9 \%$ showed intermediate enhancement and $30.8 \%$ showed faint enhancement where $3.8 \%$ showed no enhancement, $25 \%$ of all benign lesions showed no enhancement, $50 \%$ faint enhancement and $25 \%$ intense enhancement. Fig. (6). 


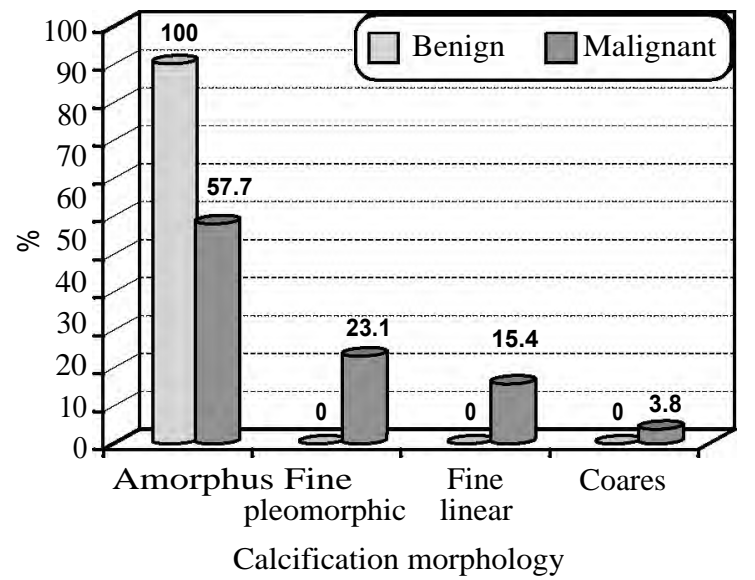

Fig. (5): Classification of microcacification morphology.

Clinical background: 47 years old female with left breast mass.

\section{Mammography revealed:}

- Breast density: ACR C

- Left breast ill-defined suspicious mass with pleomorphic malignant calcifications is seen in

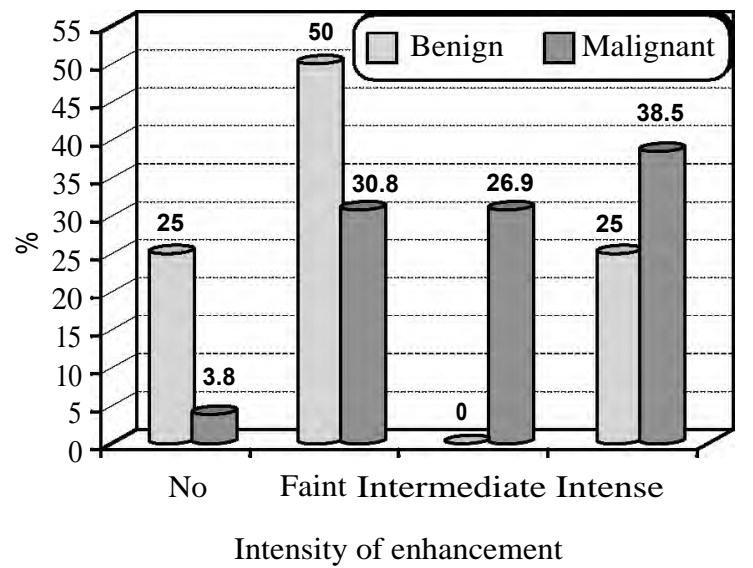

Fig. (6): Intensity of CEDM enhancement in relation to histopathology results.

the UOQ of the breast associated with skin thickening. BIRADS IV. Fig. (7).

Contrast Enhanced Mammography revealed: A heterogeneous intense enhancing mass is seen at the UOQ of the left breast. Operative recurrence BIRADS V. Fig. (7).

Final Diagnosis as proven by histopathology: Invasive ductal carcinoma.
Fig. (7): CC views (top) and MLO views (bottom) of mammography and CEDM showing left breast ill-defined suspicious mass with pleomorphic malignant calcifications is seen in the UOQ associated with skin thickening. CEDM shows a heterogeneous intense enhancing mass is seen at the UOQ of the left breast.
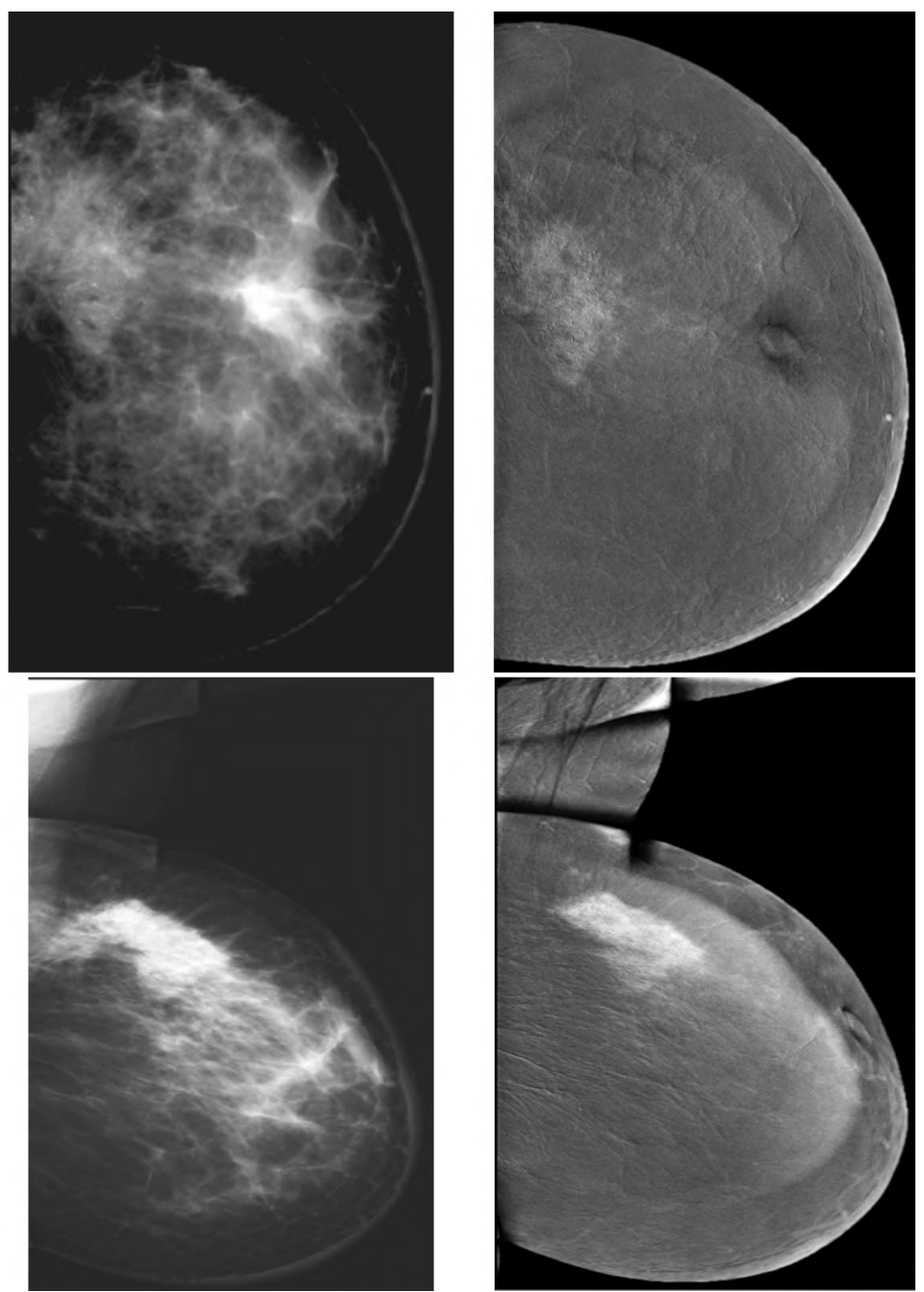
Clinical background: 37 years old female, with right breast upper central palpable mass.

\section{Mammography revealed:}

- Dense scattered fibroglandular tissue, (ACR C).

- Low energy images of the right breast revealed an UOQ and central non circumscribed speculated mass lesion, another adjacent similar but smaller satellite lesions mostly subcentemetric in size are also seen.
- Related grouped pleomorphic calcifications are seen.

- An enlarged axillary lymph node is seen with globular shape and effaced fatty hilum, measuring $1.8 \times 1.1 \mathrm{~cm}$. Fig. (8).

Contrast Enhanced Mammography revealed: The lesion showed intense mass enhancement in the combined post contrast images. Fig. (8).

Histopathology results: Invasive duct carcinoma.

Fig. (8): CC views (top) and MLO views (bottom) of mammography and CEDM showing an UOQ and central non circumscribed speculated mass lesion, related grouped pleomorphic calcifications are seen. CEDM revealed intense mass enhancement.
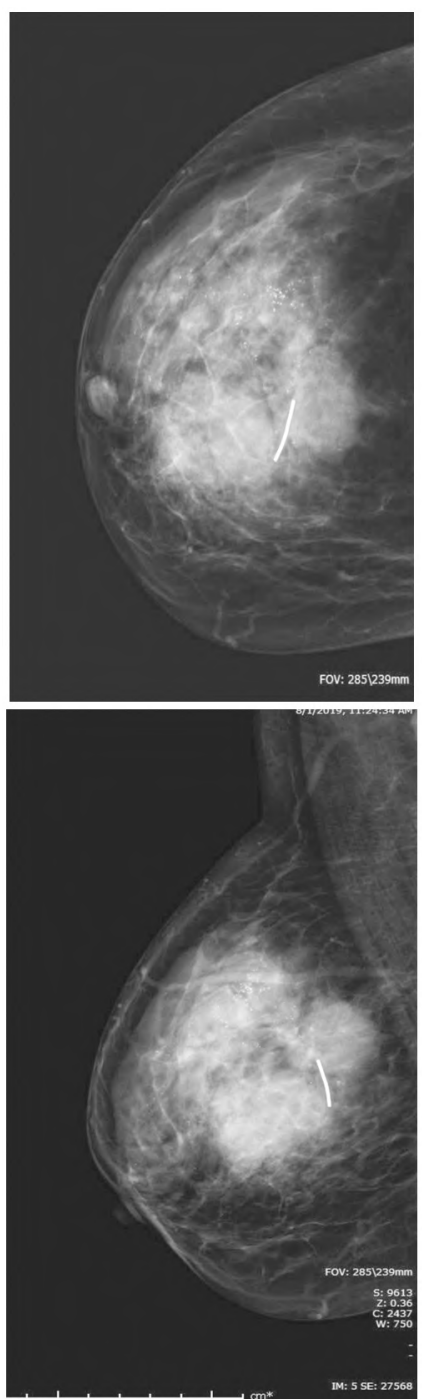
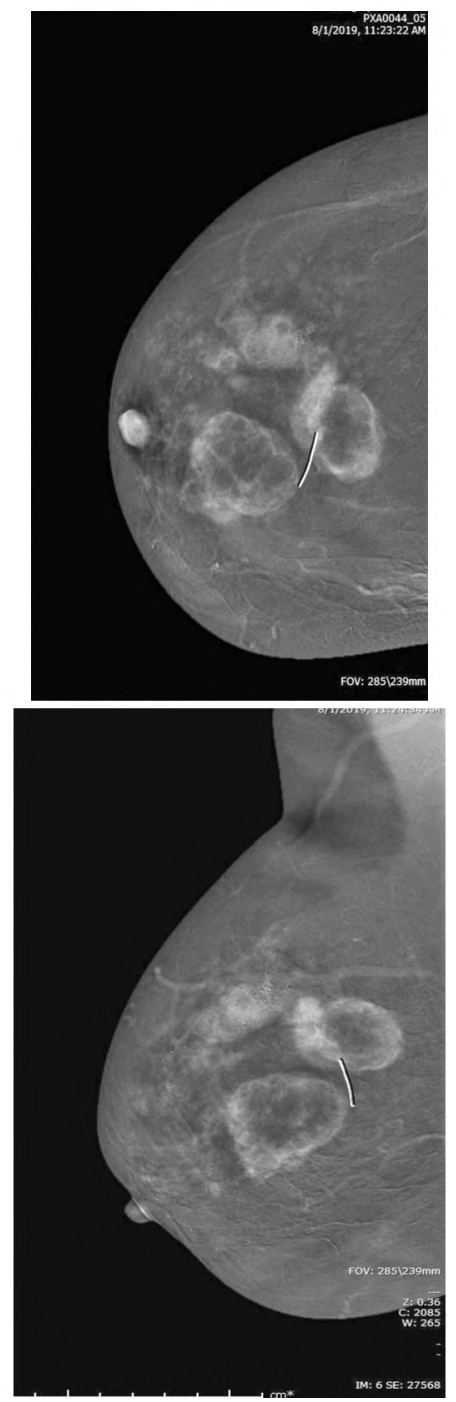

\section{Discussion}

This study was conducted on 30 patients, the ages ranged from 34-67 years with a mean of $51.27 \pm 9.24$ (mean \pm SD). The Patients that had CEDM examinations were those having mammographic suspicious breast calcifications under BIRADS 4, 5 and 6 categories.

Upon correlating with final diagnosis either by pathological analysis of core biopsy samples, true cut biopsy samples and post-surgical pathology specimen or close follow-up, there were $26 / 30$ (86.7\%) malignant and 4/30 (13.3\%) were benign lesions.

We calculated the sensitivity of combined mammography and ultrasound in detecting malignant pathology and it was (86.7\%).

Our result is in agreement with the study conducted by Berg et al. [6], in which the reported 
sensitivity for combined mammography \& ultrasound in detection of malignant breast lesions ranged from $(65-85 \%)$.

In another recent study by Houben et al. [7], on diagnostic accuracy of contrast-enhanced digital mammography in the evaluation of breast suspicious calcifications and impact on surgical management by low energy mammographic images combined with ultrasound showed sensitivity of $90.8 \%$.

In this study, CEDM Enhancement of malignant lesions was $25 / 26(96.2 \%)$. There were lesions of IDC in $18 / 26(69.2 \%)$, lesion of DCIS in $3 / 26$ $(11.5 \%)$, lesion of IDCS \& IDC in $3 / 26(11.5 \%)$ and lesions of ILC in 1/26 (3.8\%).

The sensitivity of CEDM in detecting malignant lesions with contrast uptake was $96 \%$ in this study.

This was in agreement with the study of Cheung et al. [8]. The sensitivity of CEDM was $89 \%$.

Houben et al. [7] also showed that sensitivity of CEDM was $93.8 \%$.

In another study, the sensitivity of CEDM in detecting the malignant enhancing lesions is $(71 \%)$ [9]. However, this study focused on the entire spectrum of breast lesions, not only on one specific subtype such as suspicious calcifications.

On a more extended CEDM study on 75 patients with 85 lesions comparing the performance of conventional mammography alone versus CEDM as an adjunct to conventional mammography demonstrated that contrast enhancement is shown in 93\% of the malignant lesions [10].

In our study, Enhancement was observed in 3/4 $(75 \%)$ benign lesions. There were $2 / 4(50 \%)$ lesions of ductectasia, 1/4 (25\%) periductal mastitis.

Different studies showed benign enhancement of the lesions was seen on different studies as 42/145 (29\%) in the study by Kamal et al. [9], 42/84 (50\%) in Diekmann et al. [10] and 9/27 (33\%) in Badr et al. [11]

Regarding the intensity of enhancement in malignant lesions, in our study; $38.5 \%$ of lesions showed intense enhancement, $26.9 \%$ showed intermediate enhancement and $30.8 \%$ showed faint enhancement where $3.8 \%$ showed no enhancement.

$25 \%$ of all benign lesions showed no enhancement, $50 \%$ faint enhancement and $25 \%$ intense enhancement. There was no significant difference between benign and malignant lesions according to contrast uptake intensity.

This is in accordance with the study by Kamal et al. [9], where $77 \%$ of the malignant lesions showed intense enhancement and $22.2 \%$ showed faint enhancement. While $83.3 \%$ of all benign lesions showed faint enhancement and $16.7 \%$ of all benign lesions showed intense enhancement.

Some malignant breast lesions as ductal carcinoma in situ and benign mass lesions like mammary adenosis and fibrocystic mammary changes are likely to present as non-mass enhancement. The characterization of non-mass enhancing lesions was more intricate than mass lesions due to the lack of adequate discriminating criteria and the lack of defined margins [12].

We encountered 2 lesions of non-mass enhancement, one of them was malignant and showed diffuse enhancement, the other one lesion was benign.

Imamura et al. [13] reported that using the enhancement pattern in differentiation between benign and malignant lesions is often difficult with non-mass like enhancement as there is no standardized method for interpreting them.

A study by Grimm et al. [14] provides insight into the histopathologic outcomes of biopsied calcifications. With an overall rate of malignancy of $25 \%$ for amorphous, $49 \%$ for fine pleomorphic, and $50 \%$ for fine linear or fine-linear branching calcifications. Among BI-RADS descriptors defined as suspicious morphology, only the coarse heterogeneous morphology in this sample approached the $2 \%$ malignancy threshold.

In our study the morphologic classification of microcalcifications was as follows: Fine linear in (13\%) of the 30 cases all of which are malignant; fine pleomorphic, (20\%) all malignant, coarse heterogeneous, (3\%) as one malignant case; amorphous, $(63 \%)$ which was $(21 \%)$ benign cases and (79\%) malignant cases; and typically benign, zero $(0 \%)$ of the 30 cases. The results proved to be statistically non-significant ( $p$-value $=0.445)$.

Compared to the study by Bent et al. [15], for the BI-RADS general categories of morphologic descriptors, $30(41 \%)$ of 73 higher probability of malignancy calcifications (pleomorphic and fine linear) were malignant, 12 (20\%) of 61 were classified as intermediate concern (amorphous and coarse heterogeneous), and zero (0\%) of 12 typically benign calcifications were malignant. The 
difference in malignancy risk among these categories was significant $(p=0.001)$. Suggesting significantly increased risk for the higher probability descriptions [15].

This study has some limitations. First, the study was retrospective in design with a limited sample size. Hence, a prospective randomized controlled study studying the impact of CEDM on surgical outcome would be needed.

Second, the population of patients represents a selected group recalled from a national screening program, where, in screening, radiologists decide whether an abnormality should be recalled. In theory, a different set of patients could been selected if other radiologists would read have the same exams.

\section{Conclusion:}

Dual-energy contrast-enhanced digital mammography is a useful technique in the diagnosis of underlying disease in mammographically detected breast microcalcifications.

The use of CEDM continues to be validated. The resulting efficiency and acceptable levels of radiation suggest that it may be a promising modality for routine screening and a potential substitute for costlier breast MRI.

CEDM can also be as useful a tool as CEMRI for surgical planning purposes. Results from more evidenced-based studies are, nevertheless, needed.

\section{References}

1- BLUEKENS A.M., HOLLAND R., KARSSEMEIJER N., BROEDERS M.J. and DEN HEETEN G.J.: Comparison of digital screening mammography and screen-film mammography in the early detection of clinically relevant cancers: A multicenter study. Radiology, 265: 707-714, 2012.

2- VERSCHUUR-MAES A.H., VAN GILS C.H., VAN DEN BOSCH M.A., De BRUIN P.C. and VAN DIEST P.J.: Digital mammography: More microcalcifications, more columnar cell lesions without atypia. Mod. Pathol., 24: 1191-1197, 2011.

3- HOBBS M.M., TAYLOR D.B., BUZYNSKI S. and PEAK R.E.: Contrast enhanced spectral mammography (CESM) and contrast enhanced MRI (CEMRI): Patient preferences and tolerance. J. Med. Imaging Radiat Oncol., 59: 300305,2015 .

4- FRIEDEWALD S.M., RAFFERTY E.A. and ROSE S.L.:
Breast cancer screening using tomosynthesis in combination with digital mammography. JAMA, 311 (24): 2499$2507,2014$.

5- WEIGERT J.M.: The Connecticut experiment; the third installment: 4 years of screening women with dense breasts with bilateral ultrasound. Breast J., 23 (1): 34-39, 2017.

6- BERG W.A., GUTIERREZ L., NESSAIVER M.S., et al.: Diagnostic accuracy of mammography, clinical examination, US, and MR imaging in preoperative assessment of breast cancer Radiology, 233: 830-849, 2012.

7- HOUBEN I.P., VANWETSWINKEL S., KALIA V., THYWISSEN T., NELEMANS P.J., HEUTS E.M., SMIDT M.L., MEYER-BAESE A., WILDBERGER J.E. and LOBBES M.B.I.: Contrast-enhanced spectral mammography in the evaluation of breast suspicious calcifications: Diagnostic accuracy and impact on surgical management Acta. Radiologica, 60 (9): 1110-1117, 2019.

8- CHEUNG Y., TSAI H., LO Y., et al.: Clinical utility of dual-energy contrast-enhanced spectral mammography for breast microcalcifications without associated mass: A preliminary analysis Eur. Radiol., 26: 1082-1089, 2016

9- KAMAL R.M., HELAL M.H., WESSAMA R., MANSOUR S.M., GODDAC I. and ALIELDIND N.: Contrastenhanced spectral mammography: Impact of the qualitative morphology descriptors on the diagnosis of breast lesions. European Journal of Radiology, 84 (6): 1049-1055, 2015.

10- DIEKMANN F., MARX C., JONG R., et al.: Diagnostic accuracy of contrast-enhanced digital of Breast Imaging Eur. Radiol., 18: 1307e18, 2008.

11- BADR S., LAURENT N., RÉGIS C., BOULANGER L., LEMAILLE S. and PONCELET E.: Dual-energy contrastenhanced digital mammography in routine clinical practice in 2013 Diagnostic and Interventional Imaging, 95 (3): 245-258, 2014.

12- NIE K., CHEN J.H., YU H.J., CHU Y., NALCIOGLU O. and SU M.Y.: Quantitative analysis of lesion morphology and texture features for diagnostic prediction in breast MRI Acad. Radiol., 15 (12): 1513-25, 2008.

13- IMAMURA T., ISOMOTO I., SUEYOSHI E., YANO H., UGA T., ABE K., HAYASHI T., HONDA S., YAMAGUCHI T. and UETANI M.: Diagnostic performance of ADC for Non-mass-like breast lesions on MR imaging Magnetic Resonance in Medical Sciences, 9 (4): 217-225, 2010.

14- GRIMM L.J., JOHNSON D.Y., JOHNSON K.S., BAKER J.A., SOO M.S., HWANG E.S. and GHATE S.V.: Suspicious breast calcifications undergoing stereotactic biopsy in women ages 70 and over: Breast cancer incidence by BI-RADS descriptors European Radiology, 27 (6): 22752281, 2017.

15- BENT C.K., BASSETT L.W., D'ORSI C.J. and SAYRE J.W.: The positive predictive value of BI-RADS microcalcification descriptors and final assessment categories American Journal of Roentgenology, 194 (5): 1378-1383, 2010. 


\section{تشخيص التكلسات المرضية بالثدى بواسطة الأشعة الرقمية

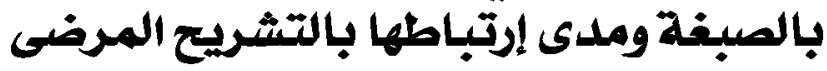

فى دراستنا، تم تصوير الثىى بالأشعة الرقمية عالية الطاقة والأشعة منخفضة الطلة ثم تم طرح الصورتين وعزل إشارة اليود فى منطقة تولد الأوعية الدموية.

بالربط مع التشخيص النهائى الناتع من التعليل المرضى لعينات الخزعة الأساسية أو عينات الخزعة المقطو عة الحقيقية سواء بعد الجراحة

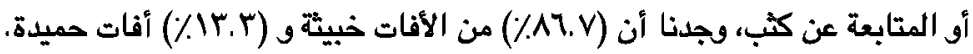

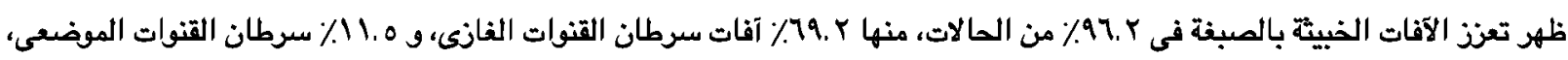

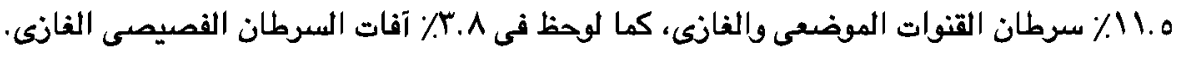
ظهر كنلك تعزز الآفات بالصبغة في No٪ من الآفات الحميدة.

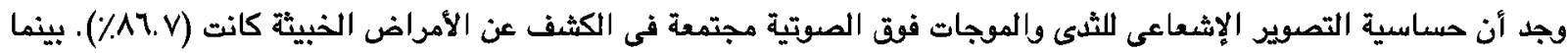
حساسية التصوير الإشعاعى الرقمى بالأشعة المعزئ بالصبغة (97٪).

فى الختام، يعد التصوير الإثعاعى للثدى الرقمى المعزذ بالصبغة ثنائى الطاقة تقنية مفيدة فى تشخيص المرض الأساسى فى التكلسات

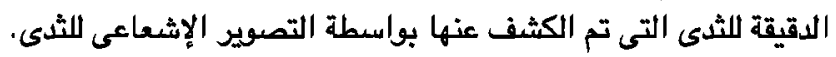

